\title{
Flexible Blasting Solution for a Variety of Steel Parts
}

\author{
An effective blasting process is essential in ensuring that the paint on steel components \\ can withstand high levels of stress. For this reason, the Dutch mechanical engineering \\ company Delwi Groenink decided to improve its manufacturing capabilities by installing \\ a new continuous feed spinner hanger blast machine for a variety of steel components.
}

Delwi Groenink, a mechanical engineering company based in the Dutch town of Enschede, designs and manufactures placement systems for containers, such as container pads, among other things. In the past the pretreatment of these components, which included manual shot blasting and the subsequent painting process, was the responsibility of external service providers. This was time-consuming and involved complex transport arrangements. To speed up the manufacturing process and allow for more flexibility, the company decided to bring these processes inhouse and took over the external companies. Delwi Groenink also invested in a shot blasting machine to improve the cost-effectiveness of the blasting process, which had previously been carried out manually. The machine was installed in a new building next to the paint shop.

\section{Excellent blasting performance and a longer service life}

The company decided on a continuous feed spinner hanger blast machine (RHBD 27/32-K) from Rösler. The machine is designed for continuous processing of single components and batches of parts up to $2600 \times 3100 \times 11,000 \mathrm{~mm}(\mathrm{H} \times \mathrm{W} \times \mathrm{L})$ in size. The blast chamber is manufactured from manganese steel. In addition, in areas exposed to the flow of blast media, it is lined with replaceable panels made from the same robust material with no gaps between them.

A total of 16 Gamma $400 \mathrm{G}$ turbines, each with a power output of $11 \mathrm{~kW}$, generate

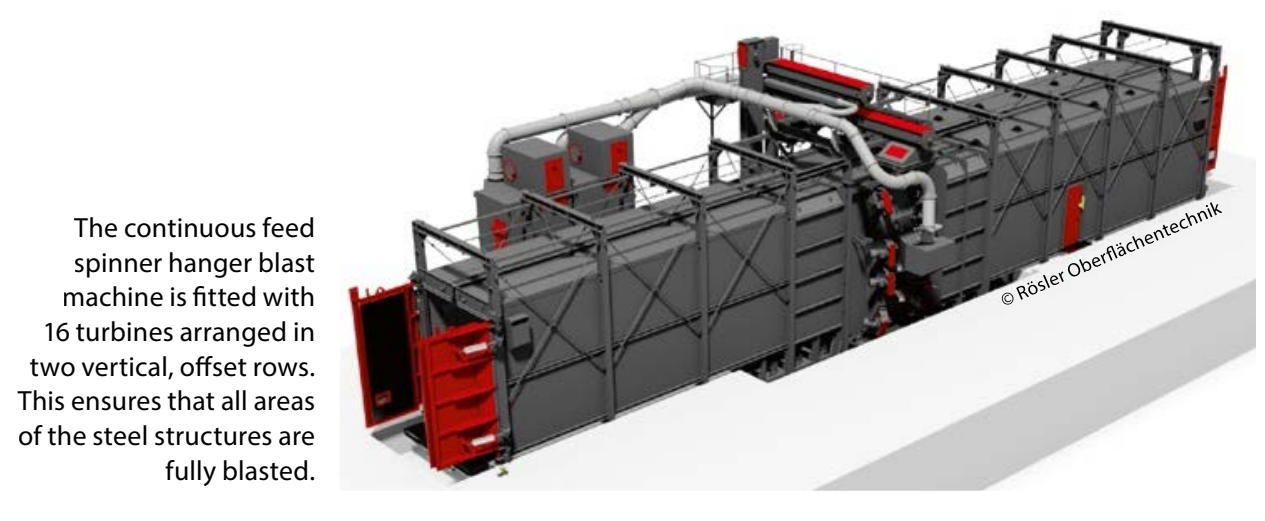

the required blasting intensity. They are arranged in two vertical, offset rows and have a throughput of blasting media of $2240 \mathrm{~kg}$ per minute, which ensures that all areas of the steel structures are fully blasted.

The special Y-shape of the blades and the improved media transfer process causes the shot to move in a very fluid way. This results in higher throwing and impact speeds, which leads to a $15 \%$ to $20 \%$ increase in blasting performance compared with conventional blast wheels of the same size.

The blasting efficiency is further improved by the concentrated blast pattern. In addition, the blades can be exchanged in only seven minutes and both sides of the blades can be used, which at least doubles their service life.

\section{A process designed to meet the customer's requirements}

Once a steel structure has been transferred to the transport beam, the machine recognises that a component is ready to be blasted and transports it into the entry chamber. As soon as the sensor monitoring the front of the blast machine indicates that there are no employees in the area, the double leaf door closes automatically.

Depending on the program, which can be selected for each type of part, some or all of the turbines start up and the component is blasted in the blasting chamber. The blasting intensity can be adjusted using frequency inverters. After the component has been transported into the exit chamber, the turbines are stopped by shell valves and then turned off. This allows the operator to manually remove blast media and dust from the component. Another sensor then checks the exit area, the doors are opened and the beam takes the component out of the machine. The media recycling and cleaning system, which consists of a bucket elevator, transverse screw conveyor and air separator, is designed to handle a throughput of around 2.5 tonnes per minute. //

\section{Contact}

Rösler Oberflächentechnik GmbH

Bad Staffelstein, Germany

Tel. +49 95339240

info@rosler.com

www.rosler.com 